The enigma of the three parallel rivers is explained as due to their valleys having been worn out along clefts through which the drainage from south-eastern Tibet was enabled to escape through the mountain rim of Chinese Tibet. This rim had been formed by the Himalayan movements which were due to the intense compression of the crust; on the relief from that pressure the mountain ranges were broken by transverse clefts, and large blocks sank between a network of fractures. The basins formed by these subsidences gave the rivers great powers of enlarging their channels and thus of excavating the deep steepsided valleys which are now the most conspicuous features in the topography of south-western China.

\title{
The Present Position of the Whaling Industry.
}

WHALING has been practised as an industry for some centuries. The pursuit of the Atlantic right whale was carried on in the Bay of Biscay at an early date, and was active at least so long ago as the twelfth century. The Greenland right whale was hunted in three areas, at successive periods, at first off Spitsbergen from about I6Io, when few Atlantic right whales were left, then in Davis Straits from about 1719 , and finally in the North Pacific and Bering Sea from about 1840 . The sperm whale, which occurred in the whole of the tropical belt, though by no means restricted to this area, was hunted from about $\times 7$.2.

The successful introduction of the modern harpoongun, with a harpoon carrying an explosive charge, dates from $x 865$, and has revolutionised whaling, by making it possible to capture the large and swift rorquals or fin whales. Modern whaling is concerned mainly with the humpback whale, the fin whale, and the blue whale, all of which are widely distributed in nearly all seas, although it is not certain whether each of these whalers' names indicates the same species in all parts of the world. After rorquals had been hunted in such localities as the Varanger

1 Substance of a paper read before the Association of Economic Biologists by Sir Sidney F. Harmer, F.R.S., on November ro.
Fjord, Newfoundland, Iceland, the British and Norwegian coasts, and elsewhere, whaling on an unprecedented scale commenced off the edge of the Antarctic Continent in I905, and is still being conducted energetically. The total catch in this area has exceeded $x 0,000$ in a single year.

The principal whale-products of economic importance are: train-oil, sperm-oil, spermaceti, baleen ambergris, whale meat, and the various forms of whale-meal or "guano." In a well-conducted factory all parts of the carcass are utilised.

With the exception of the Antarctic whaling, which has had a career of less than twenty years, whaling has been carried on consistently to an excessive amount, leading to the most serious reduction of the number of whales. The Atlantic and Greenland right whales were decimated almost to the point of extermination, the sperm whale industry has practically disappeared, and little remains now but the Antarctic whaling grounds. The efforts of all lovers of Nature should be directed to the restriction of whaling to an amount which is not inconsistent with the permanent preservation of these magnificent marine mammals and of the industry which they are so unfortunate as to support.
$\mathrm{IN}^{\mathrm{N}}$ the current issue of Biometrika (vol. xiv. pts. i. and ii.) Dr. Kirstine Smith discusses the standard deviation of a coefficient of correlation computed from data derived from classes, members of which are mutually correlated, with special reference to the case of fraternal and parental correlations calculated from entries of siblings. She finds, inter alia, that the best determination of a fraternal correlation from a given number of observations is obtained by taking $(\mathrm{I}+\mathrm{I} / \mathrm{r})$ offspring individuals from each family, where $r$ is the fraternal correlation.

Mr. Egon S. Pearson contributes an important memoir on variations in personal equation. The experimental basis of the research was a series of five sets of measurements of different type ; the form of sessional change, i.e. the resultant of factors operative within each series, is separated from the secular, or long period, change effective from one session to another ; appropriate forms for the expression of each are discussed. It is evident that in the determination of the precise value of the correlation between successive judgments in a series, one has to reckon not only with physiological or psychological common factors, the organic basis of the correlation, but also with accidental errors which blur the record-the observational errors of some writers-and reduce the numerical value of the correlation. It is found that the correlations between successive judgments decrease approximately in geometrical progression with the number of intervals, a finding consistent with the assumption that there is little or no partial correlation between the observers' true estimates at intervals greater than one. The chief practical outcome of the work is to show that although "experience and accuracy may be gained by practice, it does not follow that the correlation between successive judgments will disappear.'

\section{Studies.}

The memoir is not only of practical interest to all experimenters, but also contains several contributions to statistical algebra. In connexion with the work on pp. 37 et seq., a reference to the memoir of Anderson (Biometrika, x. 269) would have been in place, but no doubt Mr. Pearson will deal more fully with the literature of the subject in a sequel. He is to be congratulated on his first appearance in a field where one bearing his name must be judged by the highest possible standard.

Dr. Ernest Warren's paper concludes the account. of work partly described in r9I 7 concerning inheritance in the foxglove. Dr. Warren holds that " the evidence of the present investigation is therefore definitely against any general application of the theory of pure lines and of genotypes of any appreciable magnitude, and further it indicates that selective breeding within self-fertilised generations of a homogeneous race is capable of modifying that race to a marked degree."

Prof. Karl Pearson and Mr. Egon Pearson show how to find a general polychoric coefficient of correlation, i.e. to fit the " best" normal surface to data subject to the limitation that the marginal totals are exactly reproduced. The arithmetical work is heavy, and the suggestion is that a determination of the correlation ratio from the array means--not a laborious taskwill usually suffice.

Mr. James Henderson discusses the expansion of a function in tetrachoric functions, a matter of some importance to those who use the frequency systems favoured by Scandinavian mathematical statisticians.

It will be obvious that the fourteenth volume of Biometrika is as valuable to statisticians as its predecessors. 